\title{
Implementation of Energy Harvesting System of Wastes of Compressed Air Wastes for Electrical Steel Cutting Line
}

\author{
Dominik Grybos ${ }^{1, *}$, and Jacek $S$. Leszczyski ${ }^{1}$ \\ ${ }^{1}$ AGH University of Science and Technology, Faculty of Energy and Fuels, Department of Hydrogen \\ Energy, Al. Mickiewicza 30, 30-059 Krakow, Poland
}

\begin{abstract}
The pneumatic systems are commonly used in industrial plants to power pneumatic machines and tools. However, since production of compressed air is quite expensive, manufacturing plants are trying to reduce the operating costs of pneumatic systems by improving their energy efficiency. There are three main methods of reducing costs in these systems: averting energy losses, limiting input energy and harvesting energy wastes of compressed air. In this article, the authors focus on the last method mentioned above - recovering energy wastes from cutting line of electrical steel in a production plant, by using their own invention. The maximum power Pe of the device is changing from $190 \mathrm{~W}$ to $60 \mathrm{~W}$ and it depends on the value of overpressure in the tank. In one hour, the device generates about $0.07 \mathrm{kWh}$ energy and uses about $3.8 \mathrm{~m}^{3}$ of air in overpressure of 6 bar.
\end{abstract}

\section{Introduction}

The industrial pneumatic system comprises $10 \%$ of electricity consumption in European Union what is about $70 \mathrm{TWh}$ of electricity per year [1]. Moreover these systems have very poor efficiency about $10-20 \%$, so useful energy is only $7-14 \mathrm{TWh}$. The rest of the energy is lost during the preparation and use of compressed air. Most of energy losses occur in heat generated during air compressing, about 50 - $60 \%$ [5]. Moreover, air leaks in pneumatic lines, over-dimension of actuators, pressure drop and air wastes from pneumatic outlets have influence on low pneumatic system efficiency [2]. The European Union undertook the improvement of energy efficiency in the directive 2012/27/eu [3]. It underlines the need to increase energy efficiency in the EU in order to achieve a $20 \%$ reduction in primary energy consumption by 2020. The directive [3] forces industrial manufactures to improve pneumatic systems. There are multiply methods for achieving energy savings in these systems $[1,4,5]$. However, this methods are usually difficult and time-absorbing. Due to complexity and expansion of pneumatic system like different size, lot of types and amounts of actuators and different overpressure demands in elements [6]. Furthermore, the over-dimension and incorrect parameters of compressed air increase energy consumption of the pneumatic system which reduces overall energy efficiency [2]. Due to safety stock of elements and discreet

\footnotetext{
* Corresponding author: dgrybos@agh.edu.pl
} 
series of actuators, larger elements are selected than are needed. It causes higher air consumption in this element much more than it results from temporary demand.

Methods of gaining energy savings in industrial manufacturing is prevention energy losses at preparing and transporting compressed air, decrease in energy consumption and recovery air wastes $[4,5,6]$. On the market there are a lot of companies that offer comprehensive audits and treatments to reduce energy losses. For example leakage and system pressure reduction, heat recovery or reducing air consumption. The last method is based on capture exhausted air from pneumatic circuits and reuse it in other tasks. The problem of poor energy efficiency of pneumatic systems is resulted mainly of over-dimension of actuators in system [1] and can be eliminated in several different ways. For example, dual pressure circuit, individual stroke pressure or optimized pneumatic elements are well recognised methods of improving pneumatic systems [5, 7]. Moreover, compressed air may be captured and reuse in low pressure applications in pneumatic system $[4,8]$. In [10] exhausted air from a high pressure actuator was used to supply a low pressure one by accumulated air in the strain accumulator and then using it in low pressure actuators. These activities have 12 - $52 \%$ energy saving potential [7]. However, all these methods assume significant interference in the pneumatic system and machines. In a pneumatic system in which there are hundreds of actuators, it is not possible to approach them individually. Neither is to interfere in the pneumatic machines without possibilities of discalibration them.

In this paper we show different approach to oversight of over-dimension pneumatic systems. We demonstrate plug and play device to recovery exhausted air from pneumatic outlets. Our machine converts compressed air wastes to electricity. We show it implementation in manufacturing plants by connecting unit instead of the pneumatic mufflers in a Electrical Steel Cutting Line (ESCL). This leads to increase overall efficiency of ESCL in the industrial plant by recovering energy wastes from pneumatic outlet. We have made an attempt to estimate the energy efficiency in the pneumatic system and a simple calculation of the return time of the investment in the device.

\section{Experimental details}

The Electrical Steel Cutting Line (ESCL), shown in Fig. 1a, is a machine for preparing steel sheets for the construction of transformer cores. The machine realises two coordinated tasks: passing steel sheets and cutting them. The machine is supplied by compressed air from industrial pneumatic line with overpressure between $6-8$ bar. In the ESCL air is separated to two different subsystems associated with production tasks. Each pneumatic subsystem in ESCL has two pneumatic outlets showed in Fig. 1a. The outlets K1 and K1' are responsible for feeding the tape and the return of the feeder, respectively. The pair of outlets K2 and K2' is connected with cutting subsystem. After performing the tasks in the ESCL, compressed air is thrown away by pneumatic mufflers installed in outlets $\mathrm{K} 1, \mathrm{~K} 1$ ', $\mathrm{K} 2$ and $\mathrm{K} 2$ '. The air flow in the outlet $\mathrm{K} 1$ is the same as in the K1' and the air flow in the outlet $\mathrm{K} 2$ is the same as in the K2'. The machine is adapted to cutting various types of steel sheets of various sizes, length and shape. The type of cut sheet depends on the sequence of the machine in a cycle. During the test the machine worked in one setting. In the tested setting, the cycle consisted of the following: feeding, returning feeder and cutting was $0.6 \mathrm{~s}, 0.2 \mathrm{~s}$ and $2.4 \mathrm{~s}$, respectively. The machine was cutting steel sheets with $0.5 \mathrm{~mm}$ thickness and $60 \mathrm{~mm}$ of length. 

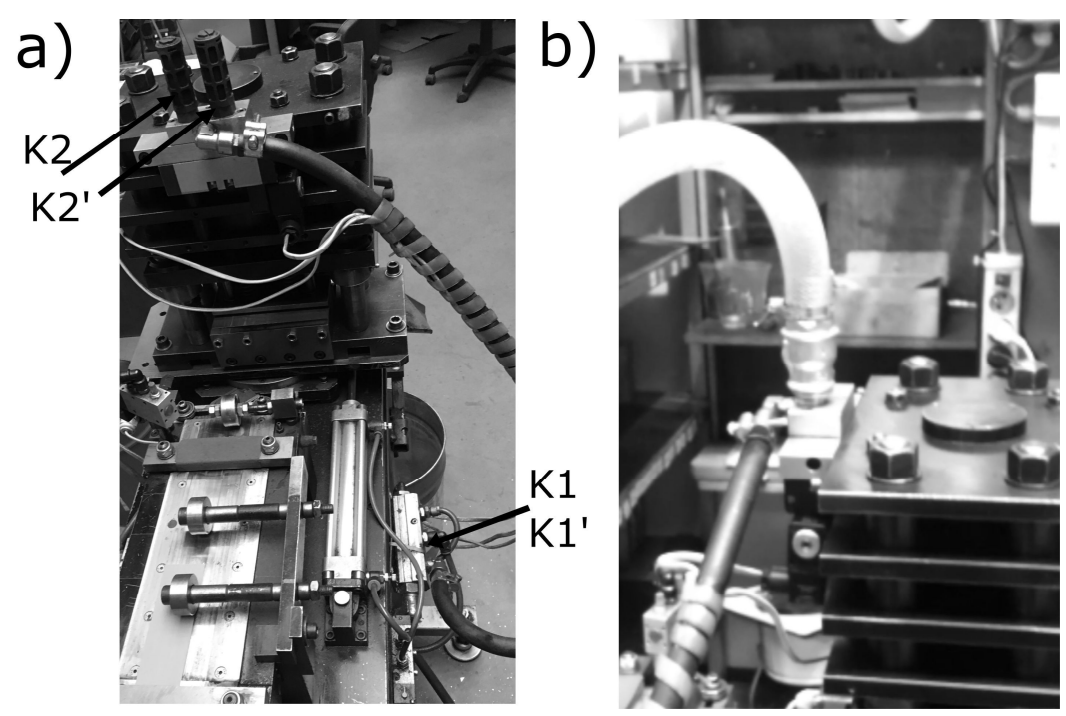

Fig. 1. The Electrical Steel Cutting Line (ESCL): a) with pneumatic outlets marked; b) with connection to $\mathrm{EH}$ unit.

To asses potentially energy savings in the ESCL, authors executed measurement of air flow from pneumatic outlets. The test consisted of measuring the time $t$ needed to raise the pressure in the tank of specific volume from overpressure 0 bar to overpressure 1.5 bar. Then by calculating the mass increase in the tank and dividing it by time, mass and volume flow of air was obtained. The several measurements were made and the result was averaged.

The Energy harvester (EH) unit was attached to the ESCL instead of one pneumatic muffler K2, like is shown in Fig. 1b. The EH unit is self - constructed and patented [11, 12] device to recovery pneumatic wastes from machine in industrial plants and conversion them into electricity. The EH unit is the plug and play technology. It is installed as overlay on the pneumatic outlet in industrial machine. The idea of recovery pneumatic energy from pneumatic systems by the EH unit is based on dynamic behavior of actuator, critical mass flow $[13,14]$ from cylinder and over-dimension of actuator in pneumatic system [4].

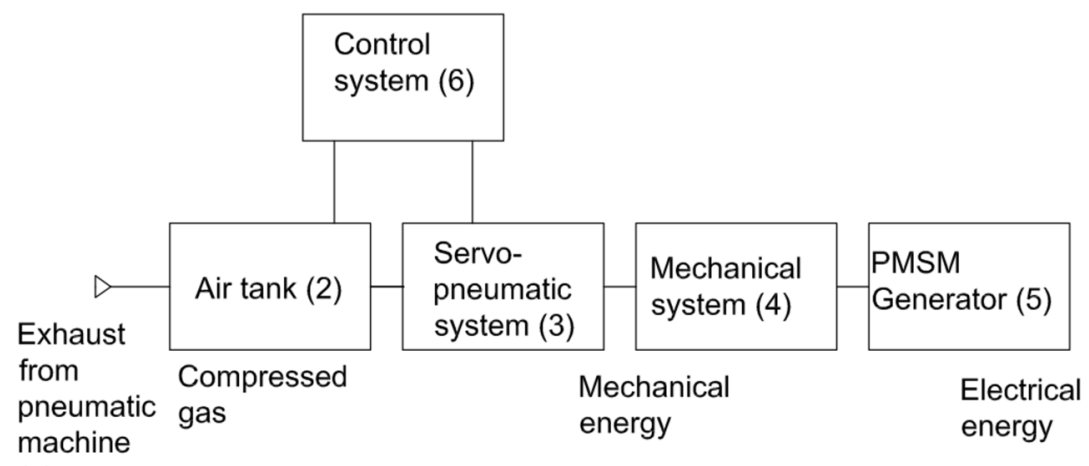

(1)

Fig. 2. Block scheme of the Energy Harvester unit.

The principle of operation of the device depends on a two-stage expansion of the compressed air from system overpressure $(6-8$ bar) to ambient pressure. The EH unit (Fig. 2 and Fig. 3) accumulates pneumatic air wastes from industrial system (1) in a storage tank 
(2). Then, energy of compressed air is converted into mechanical energy in a servo-pneumatic system (3). Next, power is transported by a mechanical system (4) and is converted into electricity in a Permanent Magnet Synchronous Generator PMSG (5). The compressed air wastes from the ESCL (1) is captured and stored in the air tank (2) of 3001 in cyclical small portions. Overpressure in the tank (2) is rising and when achieves value of 1.5 bar, the control system (6) recharges the tank (2) by the servo-pneumatic system (3) until overpressure in the air tank reaches 0.75 bar. So, the EH unit works with average overpressure 1.13 bar. The air from the tank (2) is alternately inserted through the pneumatic valve into the chambers under and over the piston in the actuator.

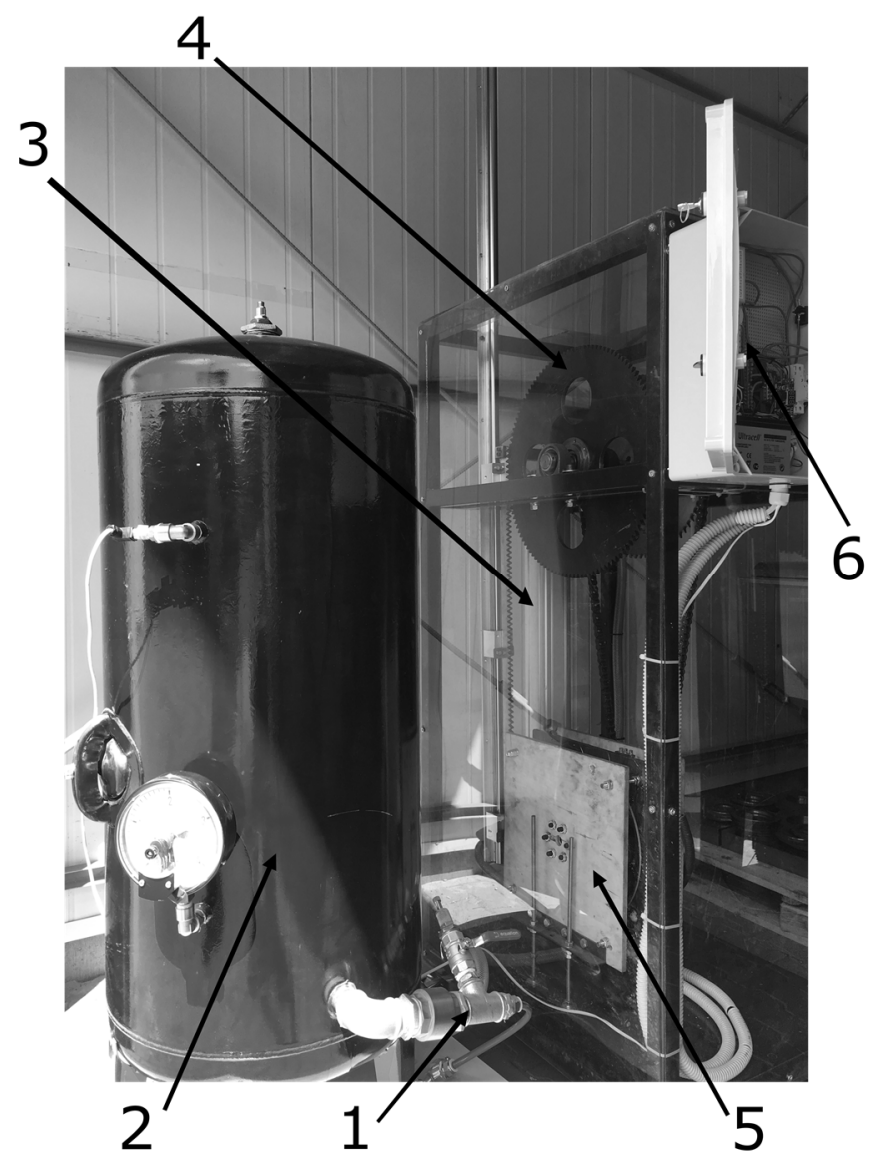

Fig. 3. The Energy Harvester unit. 1 - inlet of exhausted air, 2 - air tank, 3 - servo pneumatic system, 4 mechanical elements, 5 - PMSG generator, 6 - control system.

The pneumatic actuator has stroke $1 \mathrm{~m}$ and the piston diameter $80 \mathrm{~mm}$. The piston rod, which is connected to the generator by the mechanical gear system with the gear ratio of 20 , is moving up and down. Such move causes rotation of the PMSG's rotor and generation of electricity. The PMSG nominal velocity is $100 \mathrm{rpm}$, nominal voltage is $24 \mathrm{~V}$, nominal power is $200 \mathrm{~W}$ and number of pole pairs 24 . The measurement of the $\mathrm{EH}$ unit during the device's operation has been noted by National Instrument LabView software connected to an electronic DC load with data acquisition module with sampling rate of $10 \mathrm{kHz}$ and the 
resolution of voltage and current was $0.1 \mathrm{mV} / 0.1 \mathrm{~mA}$. The resistance value in the electronic DC load was set at value $4 \Omega$ and $5 \Omega$, which was changed during operation.

\section{Results}

The first test depended on recognition and assessment of the flow of compressed air in the ESCL. Since the tested machine did not have a main valve terminal, each actuator had separate outlet nozzles. This allowed to determine the operation of the actuators in time relative to each other. The test was performed for each of the pneumatic outlet separately. Next, the time between the beginning of the cycle and the discharge of waste air was determined by the respondent spigot. The collected data allowed to create a work graph of a given outlet nozzle in time. The curve in Fig. 4 takes high value when the air is thrown away through the given nozzle, or low value in otherwise.

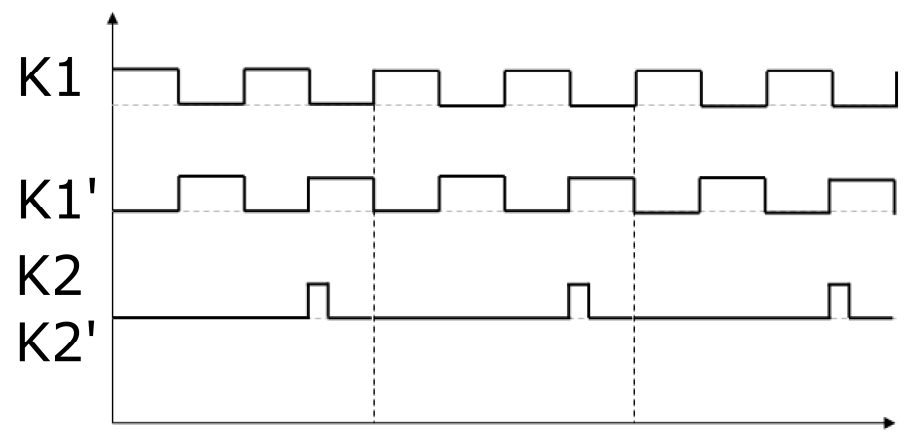

Fig. 4. Cyclicality of throwing away compressed air from the ESCL.

Table 1. The air flow measurement of pneumatic outlets in ESCL.

\begin{tabular}{|c|c|}
\hline Pneumatic outlet & Air flow $@$ 6 bar $\left[\mathbf{m}^{\mathbf{3}} \mathbf{h} \mathbf{]}\right.$ \\
\hline K1/K1' & 0.5 \\
\hline K2/K2' & 3.8 \\
\hline
\end{tabular}

Table 1 presents results from air flow measurement. The air flow of overpressure 6 bar from the pneumatic outlets $\mathrm{K} 2$ and $\mathrm{K} 2$ ' of cutting subsystem is $3.8 \mathrm{~m}^{3} / \mathrm{h}$. In passing subsystem the air flow of overpressure 6 bar is $0.5 \mathrm{~m}^{3} / \mathrm{h}$ (pneumatic outlets $\mathrm{K} 1$ and $\mathrm{K} 1$ '). So, the total amount of air of overpressure 6 bar ejected from the ESCL is about $8.6 \mathrm{~m}^{3} / \mathrm{h}$. The EH unit has air flow of overpressure 6 bar efficiency about $4 \mathrm{~m}^{3} / \mathrm{h}$, so it was connected only for one pneumatic outlet K1. Fig. 5. shows potential energy loss in the ESCL with assumption that energy from decompression from 6 bar to $1.5-0.75$ bar is needed to execute its tasks. On this condition theoretical energy wastes are $0.371 \mathrm{kWh}$ for utilizing air at average overpressure 1.13 bar $(1.5-0.75$ bar $)$. However, the boundary of overpressure value is not fixed and should be set individually. It depends of geometry parameter and size of overdimension of pneumatic machine. For example at critical overpressure set at 3 bar energy saving will be 0.793 , and for 2 bar will be $0.602 \mathrm{kWh}$. 


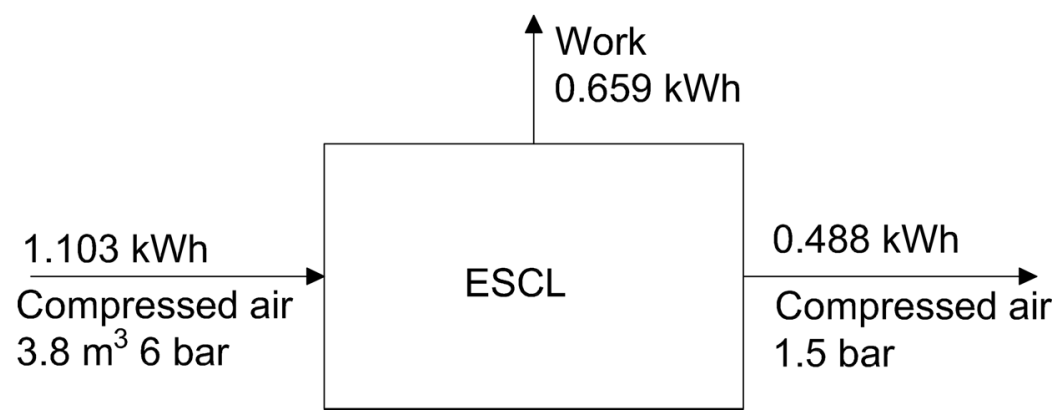

Fig. 5. Energy balance in the ESCL without compressed air recovery.

The EH unit was implemented into the ESCL by attaching the device to the outlets of the pneumatic machine operating at an overpressure of 6-8 bar (see Fig. 1b). The one operation cycle of the device after charging the tank with air, is defined as discharging the storage tank from the overpressure 1.4 bar to the overpressure 0.75 bar. Fig. 7 illustrates the work of the device connected to a source that continuously supplies air to the tank. It shows average overpressure in air tank during work cycle and electricity generated by the PMSG. The electricity power is generated in pulses during upward movement of the piston, the downward move of the piston is idly state. The mechanical transmission used in the demonstrator is limited in the form of a one-way power transmission, i.e. only when the actuator moves upwards, power is transferred to the generator shaft. After $33 \mathrm{~s}$ load resistance in the EH unit was changed from $4 \Omega$ to $5 \Omega$. This phenomena shows that exists an optimal work point of PMSG where generator efficiency is the highest. It follows that load point of PMSG is not fitted. The generated power peaks decrease during work of the EH unit because overpressure in tank is decreasing. After the measurements, it was found that the EH unit did not negatively interfere with the ESCL operation. The EH unit movement tests showed no perturbations in the system or negative phenomena. The execution times of individual tasks of the ESCL mentioned in Experimental Setup have not changed. In the pneumatic system, actuators are always over dimension and can carry out much more load. By adapting the EH unit to pneumatic outlets the lower overpressure is set to initial pressure but the pressure difference between two side of the piston is constant.

The maximum power $\mathrm{P}_{\mathrm{e}}$ of the device was changing from $190 \mathrm{~W}$ to $60 \mathrm{~W}$ and it depended on the value of overpressure in the tank (see Fig. 6). The average maximum power of the EH device was $130 \mathrm{~W}$ and the average power of the entire cycle was $75 \mathrm{~W}$. Within $1 \mathrm{~h}, 0.070$ $\mathrm{kWh}$ was produced, consuming $3.8 \mathrm{~m}^{3}$ of air during the process. Fig. 7 shows energy savings in the pneumatic system after installing the EH unit. The EH unit recovery $0.07 \mathrm{kWh}$ of potentially energy savings $0.371 \mathrm{kWh}$. So, energy efficiency of the $\mathrm{EH}$ unit was about $18 \%$ and the energy savings in ESCL was $6 \%$ in comparison to inlet energy. Low value of this parameter resulted from construction drawbacks. The reason for this is the generation of electricity only in the upward movement of piston. Moreover, wrongly selected work point from the generator's electrical side increases energy loss in PMSG. 


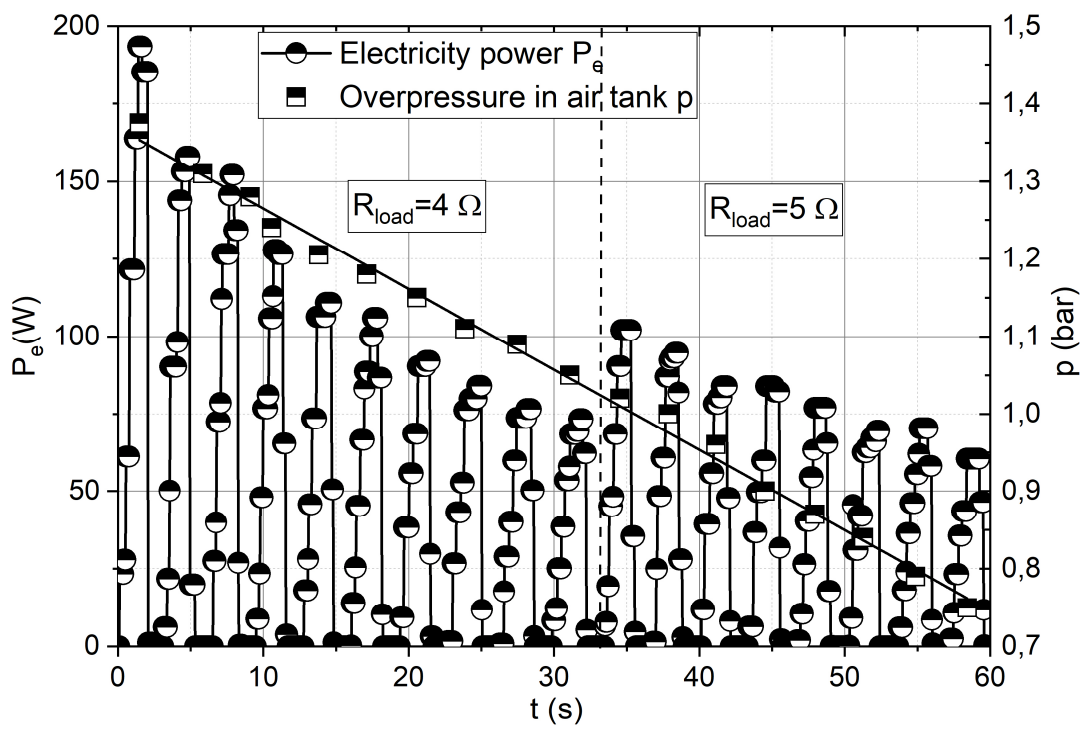

Fig. 6. Generated electricity power $P_{e}$ and overpressure drop $p$ of air during discharge of tank with change of generator load.

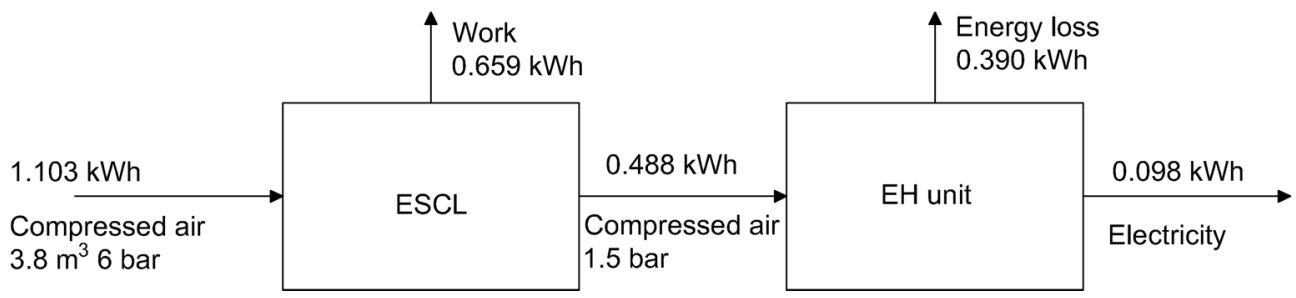

Fig. 7. Energy balance in the ESCL with the EH unit.

With such parameters of the system, assuming the working time of the EH unit in a double-shift mode for 5 working days a week (about $5000 \mathrm{~h}$ per year), it gives electricity production of $350 \mathrm{kWh}$ per year. After modifying the EH unit to two-way mode of power transfer and assuming operating in optimal point, the energy efficiency increases to about 80 $\%$. Assuming the scalability of the phenomenon and air flow efficiency to $10 \mathrm{~m}^{3} / \mathrm{h}$, the EH unit of rated power of $0.75 \mathrm{~kW}$ has been received. During work for $5000 \mathrm{~h}$ per year, the EH unit will produce about $4 \mathrm{MWh} /$ year of electricity. The production of electricity for own use seems to be much more profitable than putting energy into the grid. It should be noted that the total cost of electricity for an enterprise varies within $0.55 \mathrm{PLN} / \mathrm{kWh}$. According to the calculations made in previous considerations, the EH unit can achieve $4 \mathrm{MWh} /$ year, which gives a saving of $2200 \mathrm{PLN} /$ year. Thus, the rate of return on investment will be $4-5$ years.

\section{Conclusion}

Authors demonstrated implementation of the Energy Harvester unit to the Electrical Steel Cutting Line ESCL. The industrial test confirms usability of EH unit and the idea of improving the efficiency of pneumatic systems. The EH unit did not have influence on the ESCL working cycle. During one hour of co-working of EH unit and ESCL, $0.70 \mathrm{kWh}$ of 
electricity was saved and $3.8 \mathrm{~m}^{3}$ of compressed air was utilized. The EH unit had energy efficiency about $19 \%$ and energy savings in ESCL was $6 \%$ compared to inlet energy. However, the energy saving technology of capture air wastes from pneumatic system has much more potential. The installation of adequate power of such a device for air capacity in a pneumatic system can bring economic effect to production plants. However, it should be noted that there are some defects of the device, mainly unidirectional operation and a small overall efficiency of $19 \%$. The poor efficiency results from air losses during the downward movement of the actuator and pulsed operation of the PMSG. Theoretically it is possible to save even $4 \mathrm{MWh} /$ year but it demands construction development. The developed technology is a plug and play solution for compressed air energy saving, with relatively fast rate of return.

\section{References}

1. R. Saidur, N. A. Rahim, M. Hasanuzzaman, Renew. Sust. Energ. Rev., 14, 1135-1152 (2010)

2. E. Rakova, J. Weber, Procedia Eng., 106, 149-157 (2015)

3. Council of European Union, Directive 2012/27/eu, Official Journal EU (2012)

4. J. Hepke, J.Weber, The 13th Scandinavian International Conference on Fluid Power SICFO2013, 475-483 (2013)

5. P. Harris, G. E. O'Donnell, T. Whelan, 19th CIRP International Conference on Life Cycle Engineering, 363-368 (2012)

6. J. Hepke, J. Weber, The 7th International Fluid Power Conference, 1-5 (2012)

7. P. Harris, S. Nolan, G. E. O'Donnell, J. Clean. Prod., 72, 35-45 (2014)

8. H. Ali, S. Noor, S. M. Bashi, M. H. Marhaban, Int. J. Basic Appl. Sci. Res 3, 440-454 (2009)

9. H. Du, W. Xiong, Z. Jiang, Q. Li, L. Wang, J. Clean. Prod., 184, 511-519 (2018)

10. J. J. Cummins, C. J. Nash, S. Thomas, A. Justice, S. Mahademvan, D. E. Adams, E. J. Barth, Appl. Energy, 198, 239-249 (2017)

11. J. S. Leszczynski, K. Kastelik, R. Kaminski, et. al., UPRP PAT. 228304 (2018)

12. J. S. Leszczynski, D. Grybos, UPRP P.422009 (2018)

13. J. M. Tressler, T. Clement, 2002 IEEE International Conference on Robotics and Automation, 3248-3253 (2002)

14. Y. A. Cengel, M. A. Boles, Thermodynamics. An Engineering Approach (Mc.Graw-Hill Education, 2015) 